\title{
Comparison of two pandemics: H1N1 and SARS-CoV-2
}

\author{
Aydın Kant ${ }^{1 *}$ (1), Uğur Kostakoğlu² (D), Özlem Bayraktar Saral ${ }^{3}$ (D), Şenol Çomoğlu ${ }^{4}$ (D),

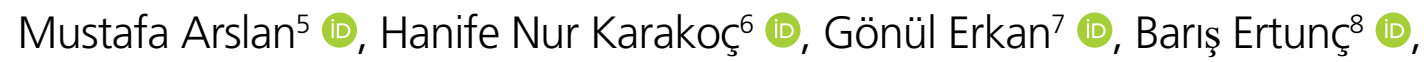

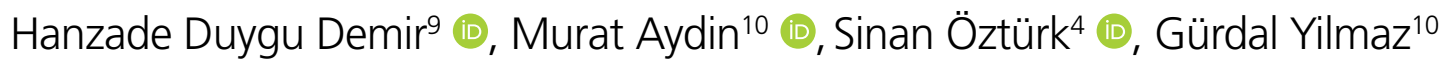

\section{SUMMARY}

OBJECTIVE: We aimed to compare the clinical, epidemiological, and prognostic features of the H1N1 pandemic in 2009 and the severe acute respiratory syndrome coronavirus 2 pandemic in 2020.

METHODS: This retrospective study involved subjects from seven centers that were admitted and found to be positive for H1N1 or COVID-19 real-time polymerase chain reaction test.

RESULTS: A total of 143 patients with H1N1 and 309 patients with COVID-19 were involved in the study. H1N1 patients were younger than COVID-19 ones. While $58.7 \%$ of H1N1 patients were female, 57.9\% of COVID-19 patients were male. Complaints of fever, cough, sputum, sore throat, myalgia, weakness, headache, and shortness of breath in H1N1 patients were statistically higher than in COVID-19 ones. The duration of symptoms until H1N1 patients were admitted to the hospital was shorter than that for COVID-19 patients. Leukopenia was more common in COVID-19 patients. C-reactive protein levels were higher in COVID-19 patients, while lactate dehydrogenase levels were higher in $\mathrm{H} 1 \mathrm{~N} 1$ ones. The mortality rate was also higher in H1N1 cases.

CONCLUSIONS: The severe acute respiratory syndrome coronavirus 2 pandemic is a major public health problem that continues to affect the world with its high rate of contagion. In addition, no vaccines or a specific drug for the benefit of millions of people have been found yet. The H1N1 pandemic is an epidemic that affected the whole world about ten years ago and was prevented by the development of vaccines at a short period. Experience in the H1N1 pandemic may be the guide to prevent the COVID-19 pandemic from a worse end. KEYWORDS: Coronavirus infections. Influenza A virus, H1N1 subtype. Pandemics.

\section{INTRODUCTION}

Infectious diseases continue to pose a great threat to public health, despite the current improvements of science and technology. Some of these illnesses are seen sporadically, while others cause epidemics worldwide. Increasing world population, nutritional problems, globalization, tourism, and economic reasons have led people to establish a connection with animals in their natural habitats. This situation has caused humans to

\footnotetext{
${ }^{1}$ Trabzon Vakfikebir State Hospital, Department of Chest Diseases - Trabzon, Turkey.

${ }^{2}$ Recep Tayyip Erdoğan University, Faculty of Medicine, Department of Infectious Diseases and Clinical Microbiology - Rize, Turkey.

${ }^{3}$ Health Sciences Unıversıty Trabzon Kanunı Traınıng And Research Hospıtal, Department of Infectious Diseases and Clinical Microbiology - Trabzon, Turkey. ${ }^{4}$ University of Health Sciences Istanbul Ümraniye Training and Research Hospital, Department of Infectious Diseases and Clinical Microbiology - Istanbul, Turkey. ${ }^{5}$ Amasya University, Faculty of Medicine, Department of Infectious Diseases and Clinical Microbiology - Amasya, Turkey.

${ }^{6}$ Tatvan State Hospital, Department of Infectious Diseases and Clinical Microbiology - Bitlis, Turkey.

7University of Health Sciences, Trabzon Ahi Evren Thoracic and Cardiovascular Surgery Education and Research Hospital, Department of Anesthesiology and Reanimation - Trabzon, Turkey.

${ }^{8}$ Akçaabat Haçkalı Baba State Hospital, Department of Infectious Diseases and Clinical Microbiology - Trabzon, Turkey.

${ }^{9}$ Trabzon Vakfıkebir State Hospital, Department of Internal Medicine - Trabzon, Turkey.

${ }^{10}$ Karadeniz Technical University, Faculty of Medicine, Department of Infectious Diseases and Clinical Microbiology - Trabzon, Turkey

*Corresponding author: aydinkant@yahoo.com

Conflicts of interest: the authors declare there is no conflicts of interest. Funding: none.

Received on November 01, 2020. Accepted on December 10, 2020.
} 
face many zoonotic diseases, such as Crimean Congo hemorrhagic fever, swine flu, bird flu, severe acute respiratory syndrome (SARS), Middle East respiratory syndrome (MERS), and the spread of these diseases on a global scale. The World Health Organization Emergency Committee announced the H1N1 influenza pandemic in 2009, polio 'resurrection' and the Ebola epidemic in 2014, and the Zika virus disease in 2016 as public health emergencies ${ }^{1}$.

The World Health Organization declared the severe acute respiratory syndrome coronavirus 2 (SARS-CoV-2) disease as a pandemic in March 2020 after the global H1N1 influenza threat in $2009^{2,3}$. Respiratory viruses that can be transmitted from person to person are responsible for both pandemics. Although rapid vaccines were produced during the H1N1 pandemic in 2009 and most cases were mild, 100,000 to 400,000 deaths due to this disease were estimated in the first year worldwide. However, there is no vaccine to protect people against COVID-19 yet. Avoiding close contact with COVID-19 infected individuals and hand washing are the only ways to prevent this disease ${ }^{4}$. Currently, this disease has caused more than 1,000,000 deaths.

In our study, we aimed to compare the clinical, epidemiological, and prognostic features of the $\mathrm{H} 1 \mathrm{~N} 1$ pandemic in 2009 and the SARS-CoV-2 pandemic in 2020.

\section{METHODS}

Our study was performed with $143 \mathrm{H} 1 \mathrm{~N} 1$ cases and 309 SARS-CoV-2 cases, which were diagnosed in eight centers in Turkey between November 2009 and January 2010 and between March-May 2020 retrospectively. The diagnosis of all H1N1 and SARS-CoV-2 cases was confirmed through the real-time polymerase chain reaction (RT-PCR) test. Demographic data (age and gender), comorbid diseases, clinical symptoms (fever, cough, sputum, dyspnea, sore throat, myalgia, weakness, nausea, vomiting, diarrhea, and headache), findings (body temperature, pulse, respiratory rate), laboratory tests, anti-microbiological treatment, respiratory support, complications, and mortality information of the patients were recorded in the study form by examining the patients' files.

\section{Statistical analysis}

Descriptive statistical analysis was carried out for all variables investigated in the study. Compatibility with the normal distribution of data obtained by the measurement was found by using the Kolmogorov-Smirnov test. Student's $t$-test was applied for the data that fit the normal distribution, and Mann-Whitney $U$ test was used for the data that did not. The $\chi^{2}$ test was used in the analysis of categorical variables. Data obtained by measurement are expressed as mean \pm standard deviation. Information taken from counting was expressed as numbers (\%). The correlation analysis was performed by using Pearson's and Spearman's correlation tests. Receiver operating characteristic (ROC) analysis was performed to calculate the sensitivity, specificity, and negative (NPV) and positive (PPV) predictive values of statistically significant variables. A p-value lower than 0.05 was considered statistically significant.

\section{RESULTS}

The average age of 143 patients with $\mathrm{H} 1 \mathrm{~N} 1$ diagnosed during the H1N1 pandemic in 2009 was $41.7 \pm 22.2$, and the average age of 309 COVID-19 patients in the same centers in the 2020 SARS-CoV-2 pandemic was $50.2 \pm 18.9$ ( $\mathrm{p}<0.001)$. In contrast, 59 (41.3\%) H1N1 patients were male, whereas in COVID-19, there were 179 (57.9\%; OR=1.96; $\mathrm{p}=0.001$ ). The duration of symptoms until H1N1 patients were admitted to the hospital was shorter than for COVID-19 patients $(\mathrm{p}<0.001)$. Complaints of fever, cough, sputum, sore throat, myalgia, weakness, headache, and shortness of breath in $\mathrm{H} 1 \mathrm{~N} 1$ patients were statistically higher than in COVID19 ones $(\mathrm{p}<0.05)$. Leukopenia (white blood cell - WBC $<4000)$ was more common in COVID-19 patients $(\mathrm{p}<0.001)$. The C-reactive protein (CRP) value was higher in COVID-19 patients $(\mathrm{p}=0.027)$. Lactate dehydrogenase $(\mathrm{LDH})$ was higher in $\mathrm{H} 1 \mathrm{~N} 1$ patients $(\mathrm{p}<0.001)$. In other laboratory tests, no statistically significant difference was detected between the two pandemic diseases. H1N1 patients were hospitalized for less time $(\mathrm{p}<0.001)$, but they required more intensive care and mechanical ventilation $(\mathrm{p}<0.001 ; \mathrm{p}=0.004)$. The mortality rate was also statistically higher in $\mathrm{H} 1 \mathrm{~N} 1$ cases $(\mathrm{p}=0.004)$. The findings are summarized in Table 1. Odds Ratio (OR) values of categorical variables in COVID-19 or H1N1 patients are demonstrated in Figure 1.

\section{DISCUSSION}

Although the H1N1 and COVID-19 pandemics are both respiratory diseases that can spread from person to person, there are significant differences between their conditions, clinical course, and preventive measures. H1N1 influenza is a disease that has caused epidemics and pandemics of which we have a knowledge of precautions, antiviral drugs, and vaccination studies. COVID-19 pandemic, on the other hand, is a disease that the world has not experienced before and does not have sufficient infrastructure to develop specific antiviral drugs or vaccines. In our study, we compared the clinical, 
epidemiological, and prognostic features of the H1N1 pandemic in 2009 and the SARS-CoV-2 pandemic in 2020. Young people were affected more in $\mathrm{H} 1 \mathrm{~N} 1$ pandemic than in
COVID-19 ( $\mathrm{p}<0.001)$. In the H1N1 pandemic, the elderly people were relatively protected, because they were immune to H1N1 epitopes in influenza outbreaks in 1918 and later ${ }^{5}$.

Table 1. Demographic, clinical, and laboratory features of the patients.

\begin{tabular}{|c|c|c|c|c|c|}
\hline & H1N1 (n=143) & COVID $(n=309)$ & p-value & OR & $95 \% \mathrm{Cl}$ \\
\hline Age & $41.7 \pm 22.2$ & $50.2 \pm 18.9$ & $<0.001$ & {$[-]$} & {$[-]$} \\
\hline Gender (male) & $59(41.3)$ & $179(57.9)$ & 0.001 & 0.51 & $0.33-0.78$ \\
\hline Comorbidity & $50(34.9)$ & $127(41.1)$ & 0.205 & {$[-]$} & {$[-]$} \\
\hline Duration of symptom (days) & $4.5 \pm 2.6$ & $3.6 \pm 3.2$ & $<0.001$ & {$[-]$} & {$[-]$} \\
\hline Fever & $90(62.9)$ & $151(48.9)$ & 0.016 & 1.78 & $1.16-2.72$ \\
\hline Cough & $117(81.8)$ & $185(59.9)$ & $<0.001$ & 3.02 & $1.82-5.03$ \\
\hline Sputum & $50(34.9)$ & $33(10.6)$ & $<0.001$ & 4.50 & $2.65-7.64$ \\
\hline Sore throat & $74(51.7)$ & $85(27.5)$ & $<0.001$ & 2.83 & $1.83-4.36$ \\
\hline Myalgia & $91(63.6)$ & $94(30.4)$ & $<0.001$ & 4.25 & $2.72-6.64$ \\
\hline Weakness & $109(76.2)$ & $160(51.8)$ & $<0.001$ & 2.99 & $1.87-4.78$ \\
\hline Headache & $83(58)$ & 76 (24.6) & $<0.001$ & 4.24 & $2.72-6.61$ \\
\hline Nausea/Nomiting & $29(20.3)$ & $26(8.4)$ & 0.114 & {$[-]$} & {$[-]$} \\
\hline Diarrhea & $12(8.4)$ & $25(8.1)$ & 0.802 & {$[-]$} & {$[-]$} \\
\hline Dyspnea & $84(58.7)$ & $92(29.8)$ & $<0.001$ & 3.36 & $2.18-5.19$ \\
\hline WBC & $9021 \pm 5843$ & $5932 \pm 3458$ & $<0.001$ & & \\
\hline$W B C<4000$ & $16(11.2)$ & $84(27.2)$ & $<0.001$ & 0.34 & $0.18-0.62$ \\
\hline Lymphocyte count & $1193 \pm 821$ & $1501 \pm 802$ & 0.092 & {$[-]$} & {$[-]$} \\
\hline Platelet count & $189000 \pm 65000$ & $193000 \pm 65000$ & 0.780 & {$[-]$} & {$[-]$} \\
\hline $\mathrm{Hb}$ & $13.0 \pm 1.9$ & $13.4 \pm 1.7$ & 0.228 & {$[-]$} & {$[-]$} \\
\hline CRP & $12.3 \pm 11.5$ & $32.9 \pm 58.1$ & 0.027 & {$[-]$} & {$[-]$} \\
\hline BUN & $30.3 \pm 23.2$ & $36.8 \pm 29.3$ & 0.031 & {$[-]$} & {$[-]$} \\
\hline Creatinin & $1.1 \pm 0.7$ & $0.9 \pm 0.2$ & 0.962 & {$[-]$} & {$[-]$} \\
\hline AST & $61.9 \pm 66.5$ & $54.0 \pm 169.2$ & 0.021 & {$[-]$} & {$[-]$} \\
\hline ALT & $58.6 \pm 83.4$ & $51.5 \pm 179.6$ & 0.419 & {$[-]$} & {$[-]$} \\
\hline LDH & $503.9 \pm 278.7$ & $323.3 \pm 153.6$ & $<0.001$ & {$[-]$} & {$[-]$} \\
\hline CPK & $319.3 \pm 431.3$ & $278.8 \pm 166.7$ & 0.909 & {$[-]$} & {$[-]$} \\
\hline PT & $13.9 \pm 1.2$ & $14.6 \pm 1.9$ & 0.075 & {$[-]$} & {$[-]$} \\
\hline aPTT & $34.2 \pm 6.2$ & $31.0 \pm 6.7$ & $<0.001$ & {$[-]$} & {$[-]$} \\
\hline INR & $1.19 \pm 0.3$ & $1.09 \pm 0.2$ & 0.003 & {$[-]$} & {$[-]$} \\
\hline Hospitalization day & $4.4 \pm 5.7$ & $10.9 \pm 7.6$ & $<0.001$ & {$[-]$} & {$[-]$} \\
\hline intensive care & $59(41.3)$ & $57(18.4)$ & $<0.001$ & 3.11 & $1.95-4.94$ \\
\hline Mechanical ventilator support & $40(28.0)$ & $28(9.1)$ & 0.004 & {$[-]$} & {$[-]$} \\
\hline Mortality & $12(8.4)$ & $10(3.2)$ & 0.004 & 2.74 & $1.07-7.04$ \\
\hline
\end{tabular}

WBC: White blood cell; Hb: Haemoglobin; CRP: C-reactive protein; BUN: Blood urea nitrogen; AST: Aspartate aminotransferase; ALT: Alanin aminotransferase; LDH: Lactate dehydrogenase; CPK: Creatine phosphokinase; PT: Protrombin time; aPTT: Activated partial thromboplastin time; INR: International normalized ratio. 
In COVID-19, although some degree of cross-protection is possible for other coronaviruses, the rapid spread of SARSCoV2 suggests that there is no immunity to the disease ${ }^{6}$. While H1N1 affected more the female gender, COVID-19 affects more males $(\mathrm{p}=0.001)$. In a meta-analysis study, $60 \%$ of COVID-19 cases were reported to be males ${ }^{7}$. This may be due to the fact that males pay less attention to protective measures and engage more in social settings. Males were also more affected in studies of MERS-COV and SARS- $\mathrm{COV}^{8,9}$. It has been emphasized that $\mathrm{X}$ chromosome and sex hormones may also be responsible for women's being less affected ${ }^{10}$. In the 2009 H1 N1 pandemic, however, women were more affected, although it varied between geographic regions. This is mainly due to the fact that women of reproductive age being more affected and admitted to hospital ${ }^{11}$. In our study, the women with H1N1 were mostly at reproductive age. The age of the women was higher in COVID-19 patients.

Although clinical symptoms at the time of admission were statistically significantly higher in $\mathrm{H} 1 \mathrm{~N} 1$ patients, COVID19 patients applied to the hospital earlier. This paradoxical situation may have resulted from the widespread usage of communication tools, especially social media compared to 2009. In addition, wider filiation by the health authorities caused more frequent admission to the hospital in the COVID-19 pandemic. Laboratory results have shown that leukopenia and elevated CRP levels are more common in COVID-19 patients and elevated LDH levels are more common in H1N1 ones. This could be related to the disease severity, levels of inflammatory cytokines released, and differences in the age and sex of the patients. During the COVID-19 pandemic, the decision to follow up in the hospital as much as possible by the health authorities to prevent contamination from patients and to prevent the circulation of these patients in the community may explain the reason of hospitalization for a longer period than in H1N1. The need for intensive care and mechanical ventilator support was higher in $\mathrm{H} 1 \mathrm{~N} 1$ patients. The mortality rate in our $\mathrm{H} 1 \mathrm{~N} 1$ patients was statistically significant higher $(\mathrm{p}=0.004)$. While H1N1 mortality was similar to global mortality rates, COVID-19 mortality rate was below them ${ }^{7,12}$.

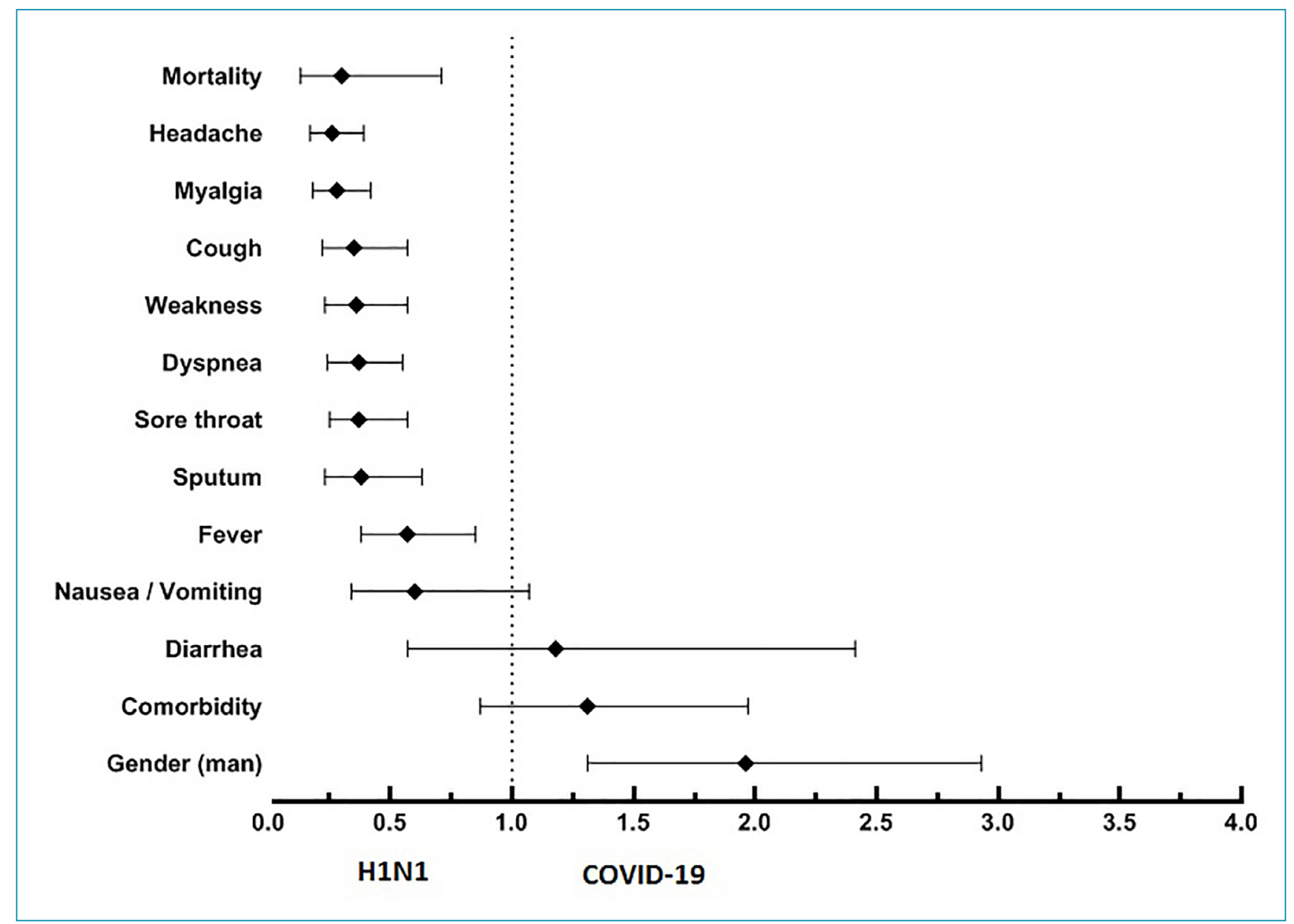

Figure 1. Plots reporting the Odds Ratio and 95\% confidence interval of categorical variables in COVID-19 or H1N1 patients. 
The number of people affected globally and of mortality rates in both pandemics were examined; although the person-to-person transmission rate was low in the H1N1 pandemic, the infected patients were faced with a more severe clinic. In the COVID-19 pandemic, the rate of transmission from person to person was quite high, although the clinic one was milder. ${ }^{2,3,7,12}$.

\section{CONCLUSION}

The SARS-CoV-2 pandemic, with its high transmission rate, is a major public health problem that continues to affect the world today, with more than one million deaths. No vaccine or specific medicine to prevent the disease have been found yet. The H1N1 epidemic, on the other hand, is an epidemic that affected the whole world about 10 years ago and was prevented by the vaccine developed at a short time, with the advantage of knowing the vaccination techniques against the influenza virus. This experience in the H1N1 pandemic may be a guide for clinicians and researchers in the management of the COVID19 pandemic.

\section{AUTHORS' CONTRIBUTIONS}

AK: Formal Analysis, Investigation, Methodology, Project Administration, Resources, Writing-Review \& Editing. UK: Investigation, Resources, Writing-Original Draft. ÖBS: Investigation. ŞÇ: Investigation. MA: Investigation. HNK: Investigation. GE: Investigation. BE: Investigation. HDD: Investigation. MA: Investigation. SÖ: Investigation. GY: Formal Analysis, Investigation, Methodology, Project Administration, Writing-Review \& Editing.

\section{REFERENCES}

1. Graham BS, Sullivan NJ. Emerging viral diseases from a vaccinology perspective: preparing for the next pandemic. Nat Immunol. 2018;19(1):20-8. https://doi.org/10.1038/s41590-017-0007-9

2. World Health Organization. Coronavirus disease (COVID-19) pandemic. Geneva: World Health Organization; 2020. [cited on Oct 12, 2020]. Available from: https://www.who.int/ emergencies/diseases/novel-coronavirus-2019

3. World Health Organization. H1N1 now in the post-pandemic period. Geneva: World Health Organization; 2020. [cited on Oct 12, 2020]. Available from: https://www.who.int/csr/disease/swineflu/en/

4. Hill B. The COVID-19 pandemic. Br J Nurs. 2020;29(8):456. https://doi.org/10.12968/bjon.2020.29.8.456

5. Xu R, Ekiert DC, Krause JC, Hai R, Crowe Jr JE, Wilson IA. Structural basis of preexisting immunity to the $2009 \mathrm{H} 1 \mathrm{~N} 1$ pandemic influenza virus. Science. 2010;328(5976):357-60. https://doi.org/10.1126/science.1186430

6. Jhaveri R. Echoes of $2009 \mathrm{H} 1 \mathrm{~N} 1$ influenza pandemic in the COVID pandemic. Clin Ther. 2020;42(5):736-40. https://doi. org/10.1016/j.clinthera.2020.04.003

7. Li LQ, Huang T, Wang YQ, Wang ZP, Liang Y, Huang TB, et al. COVID-19 patients' clinical characteristics, discharge rate, and fatality rate of meta-analysis. J Med Virol. 2020;92(6):577-83. https://doi.org/10.1002/jmv.25757
8. Badawi A, Ryoo SG. Prevalence of comorbidities in the Middle East respiratory syndrome coronavirus (MERS-CoV): a systematic review and meta-analysis. Int J Infect Dis. 2016;49:129-33. https://doi.org/10.1016/j. ijid.2016.06.015

9. Channappanavar R, Fett C, Mack M, Ten Eyck PP, Meyerholz DK, Perlman S. Sex-based differences in susceptibility to severe acute respiratory syndrome coronavirus infection. J Immunol. 2017;198(10):4046-53. https://doi.org/10.4049/ jimmunol.1601896

10. Jaillon S, Berthenet K, Garlanda C. Sexual dimorphism in innate immunity. Clin Rev Allergy Immunol. 2019;56(3):30821. https://doi.org/10.1007/s12016-017-8648-x

11. Klein SL, Passaretti C, Anker M, Olukoya P, Pekosz A. The impact of sex, gender and pregnancy on 2009 H1N1 disease. Biol Sex Differ. 2010;1(1):5. https://doi.org/10.1186/20426410-1-5

12. Dawood FS, luliano AD, Reed C, Meltzer MI, Shay DK, Cheng PY, et al. Estimated global mortality associated with the first 12 months of 2009 pandemic influenza A H1N1 virus circulation: a modelling study. Lancet Infect Dis. 2012;12(9):687-95. https://doi.org/10.1016/S14733099(12)70121-4 